\title{
Habit and Skill Learning in Schizophrenia: Evidence of Normal Striatal Processing With Abnormal Cortical Input
}

\author{
Thomas W. Weickert, ${ }^{1,3}$ Alejandro Terrazas, ${ }^{1}$ Llewellyn B. Bigelow, ${ }^{1}$ James D. Malley, \\ Thomas Hyde, ${ }^{1}$ Michael F. Egan, ${ }^{1}$ Daniel R. Weinberger, ${ }^{1}$ and Terry E. Goldberg ${ }^{1}$ \\ ${ }^{1}$ Clinical Brain Disorders Branch, National Institute of Mental Health, National Institutes of Health, Bethesda, Maryland 20892, USA; ${ }^{2}$ Center \\ for Information Technology, National Institutes of Health, Bethesda, Maryland 20892, USA
}

\begin{abstract}
Different forms of nondeclarative learning involve regionally specific striatal circuits. The motor circuit (involving the putamen) has been associated with motor-skill learning and the dorsolateral prefrontal cortex (DLPFC) circuit (involving the caudate) has been associated with cognitive-habit learning. Efforts to differentiate functional striatal circuits within patient samples have been limited. Previous studies have provided mixed results regarding striatal-dependent nondeclarative learning deficits in patients with schizophrenia. In this study, a cognitive-habit learning task (probabilistic weather prediction) was used to assess the DLPFC circuit and a motor-skill learning task (pursuit rotor) was used to assess the motor circuit in 35 patients with schizophrenia and 35 normal controls. Patients with schizophrenia displayed significant performance differences from controls on both nondeclarative tasks; however, cognitive-habit learning rate in patients did not differ from controls. There were performance and learning-rate differences on the motor-skill learning task between the whole sample of patients and controls, however, analysis of a subset of patients and controls matched on general intellectual level eliminated learning rate differences between groups. The abnormal performance offset between patients with schizophrenia and controls in the absence of learning rate differences suggests that abnormal cortical processing provides altered input to normal striatal circuitry.
\end{abstract}

Memory has been proposed to be subserved by multiple brain systems. For example, the hippocampal formation is important for the rapid acquisition of new associations with conscious awareness, which is referred to as explicit or declarative memory (Squire 1992a). Other structures, such as the cerebellum, posterior neocortex, and basal ganglia are believed to be responsible for a more gradual acquisition of new information or skills that may take place without conscious awareness, which is referred to as implicit or nondeclarative memory (Cohen and Squire 1980; Squire 1992b; Ungerleider 1995; Bailey and Kandel 1997). Animal lesion studies (Divac et al. 1967; Packard et al. 1989; Packard and McGaugh 1992; McDonald and White 1993; Aosaki et al. 1994) have demonstrated a double dissociation between striatal and hippocampal learning. Additionally, single dissociations between declarative and nondeclarative memory (for review, see Squire 1992b; Schacter et al. 1993) and double dissociations between declarative memory and emotional learning (Bechara et al. 1995) and perceptual priming (Gabrieli et al. 1995; Keane et al. 1995) have been obtained in humans.

${ }^{3}$ Corresponding author.

E-MAIL weickert@intra.nimh.nih.gov.; FAX (301) 480-7795. Article and publication are at http://www.learnmem.org/cgi/doi/ $10.1101 / \mathrm{lm} .49102$.
Only a few investigators have assessed cognitive-habit learning in schizophrenia (SC), (Goldberg et al. 1990; GrasVincendon et al. 1994; Michel et al. 1998; Bustini et al. 1999) but the task used in these studies, different versions of the so-called Tower test, has been demonstrated to recruit executive function, problem solving abilities, and working memory rather than solely nondeclarative processes ( Martone et al. 1984; Butters et al. 1985; Phillips et al. 1999; Welsh et al. 1999; Winter et al. 2001). Keri et al. (2000) reported intact cognitive-habit learning in patients with SC using a version of a probabilistic learning test originally designed to selectively assess nondeclarative habits that guide cognition (Knowlton et al. 1996a,b) (described below). However, the methods of Keri et al. (2000) differed from the original design of this task (Knowlton et al. 1996a,b) on four principle characteristics as follows: (1) manual presentation, (2) forced choice responding, (3) randomization of cue card positions, and (4) high percentage of discarded or correctly predicted cue card combinations, which may have resulted in changes to the nondeclarative and/or probabilistic nature of the task.

Studies examining nondeclarative learning in patients with SC on the pursuit rotor motor-skill learning task have produced mixed results, some have demonstrated impaired learning (Huston and Shakow 1949; Eysenck and Frith 1977;

LEARNING \& MEMORY 9:430-442 @ 2002 by Cold Spring Harbor Laboratory Press ISSN1072-0502/02 \$5.00

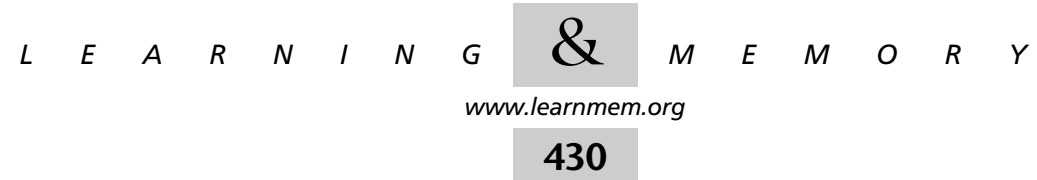


Schwartz et al. 1996) and others preserved learning (Clare et al. 1993; Goldberg et al. 1993; Granholm et al. 1993; Kern et al. 1997). These conflicting findings may reflect several methodological differences including differences in instrumentation, in equating for initial performance, in number of trials administered, and in failure to differentiate between y-intercept (i.e., absolute performance) and slope (learning rate). Further complicating the picture are influences of intrinsic moderating variables such as intellectual ability and declarative memory as well as the effect of antipsychotic medication.

Whereas Knowlton et al. (1996a) have demonstrated that the dorsolateral prefrontal cortex (DLPFC) does not appear to contribute to performance on a probabilistic habit-learning test by obtaining equivalent performances between healthy controls and a group of patients with frontal lobe damage, results from functional neuroimaging studies in healthy controls (Poldrack et al. 1999, 2001) have shown concurrent activation of both the caudate nucleus and prefrontal cortex during probabilistic habit learning. Such concurrent activation of the caudate and DLPFC would suggest that DLPFC and striatal circuitry may be implicated during cognitive habit learning in humans. Similarly, concurrent activation of the putamen and supplementary motor area during administration of the pursuit rotor motor-skill learning test (Grafton et al. 1992, 1994), would suggest that the motor circuit of the basal ganglia may be important during motor-skill learning. Because multiple forms of nondeclarative memory may be subserved by distinct neuronal circuitry in the basal ganglia, the potential to demonstrate dissociations within the system exists.

The current study assessed performances on two measures of nondeclarative learning as follows: (1) the pursuit rotor task assessed the motor circuit, and (2) a probabilistic learning test assessed the DLPFC circuit. We tested the DLPFC circuit and the question of a possible cognitivehabit learning impairment in SC using a probabilistic learning (the so-called weather prediction) task of Knowlton et al. (1996a,b). In this task, participants learn cue-outcome associations without conscious awareness of the probabilistic frequencies determining each association. The probabilistic schedule of reinforcement produces a gradual learning of associations that is analogous to habit learning in animals (Knowlton et al. 1996a,b), has been correlated with caudate and DLPFC activity in normal controls (Poldrack et al. 1999, 2001), and appears to be selective for human striatal abnormalities, as patients with frontal lobe lesions learn normally (Knowlton et al. 1996a). The data analytic approaches applied to the results of these probabilistic learning tasks by Knowlton et al. (1994) have been subsequently validated in other patient groups (Knowlton et al. 1996a,b).

Although there is indirect evidence suggesting that patients with SC possess striatal abnormalities, such as increased striatal dopamine (DA) activity in patients with SC
(Cross et al. 1981; Seeman et al. 1989; Seeman and Niznik 1990; Pilowsky et al. 1994; Laruelle et al. 1996; Lindstrom et al. 1999) and symptom reduction associated with administration of DA D2 receptor antagonists (Cole et al. 1964; Horn and Snyder 1971; Crow and Gillbe 1974; Seeman 1987; Kapur and Seeman 2001), previous studies have generally failed to display direct evidence of primary striatal dysfunction in SC (Pickar et al. 1996; Heinz et al. 1998; Bertolino et al. 1999, 2000; Meyer-Lindenberg et al. 2002). On the basis of previous evidence of DLPFC dysfunction in SC (Goldberg et al. 1988; Callicott et al. 1999, 2000) and the relationship of the striatum to the DLPFC (Alexander et al. 1986) and DLPFC activity associated with cognitive-habit learning (Poldrack et al. 1999, 2001), the first hypothesis tested was that patients with SC would display impaired cognitive-habit learning relative to healthy normal control (NC) participants.

In addition to measuring cognitive-habit learning, we assessed motor-skill learning using a pursuit rotor task. In a previous Positron Emission Tomography study of motorskill learning using the pursuit rotor in NC participants, Grafton et al. (1994) has shown that improved performance was associated with increased activity in the putamen. Because motor-skill learning has been demonstrated to be intact in the majority of recent studies of patients with SC (Clare et al. 1993; Goldberg et al. 1993; Granholm et al. 1993; Kern et al. 1997), the hypothesis tested with respect to motor-skill learning was that patients with SC would not differ from NC participants on the pursuit rotor task. If the two hypotheses regarding nondeclarative learning are supported in this study, then a dissociation would be obtained displaying preserved and impaired components within the nondeclarative/basal ganglia system in SC.

\section{RESULTS}

\section{Cognitive-habit Learning and Executive Function}

In the overall sample, relative to controls, patients with SC displayed impaired cognitive-habit performance (Fig. 1A). A two-way repeated measures ANOVA on the mean percent correct transformed scores displayed a main effect of group, $\mathrm{F}(1,68)=10.75, P<0.002$, and a significant main effect of trial, $\mathrm{F}(14,952)=19.86, P<0.001$. However, there was no significant group by trial interaction, $F(14,952)=1.33$, $P=0.185$. A separate independent t-test revealed that the slope of the learning curve over 150 trials in patients with $\mathrm{SC}($ mean $=1.2, \mathrm{SD}=2.7)$ did not differ significantly from the slope displayed by the controls (mean $=1.8, \mathrm{SD}=2.3$ ), $\mathrm{t}(68)=0.93, P>0.35$. Also, a separate independent t-test of the learning curve across the first 30 trials did not display a significant difference between patients (mean $=0.40, \mathrm{SD}$ $=6.9)$ and controls (mean $=2.8, \mathrm{SD}=5.9), \mathrm{t}(68)=1.56$, $P>0.12$. Likewise, a separate independent t-test revealed

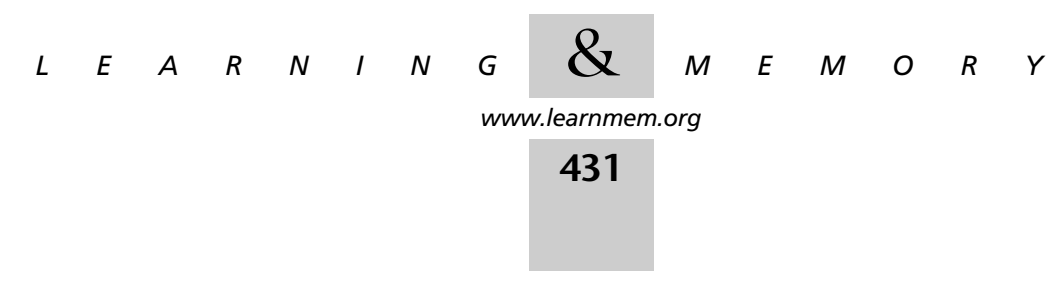



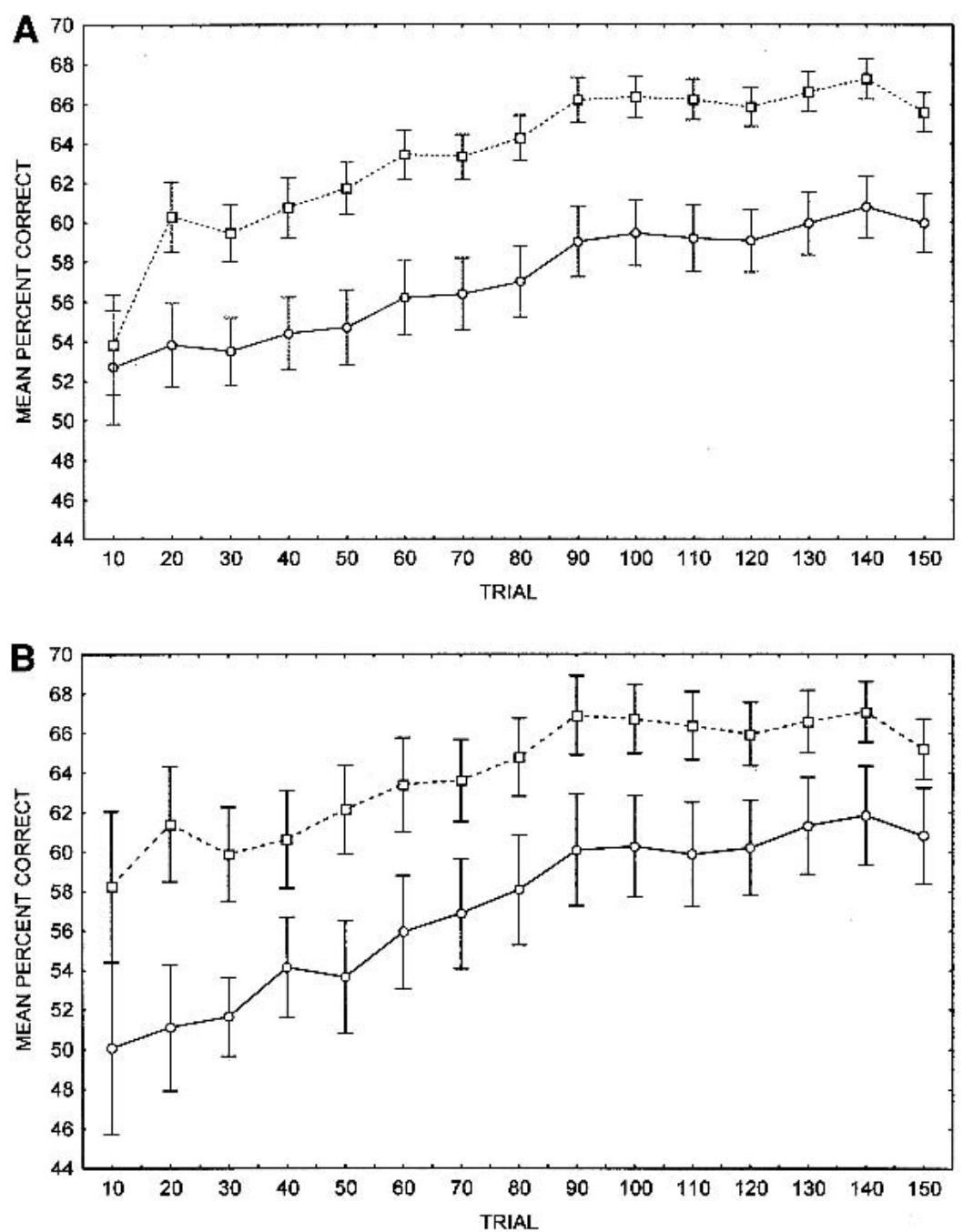

Figure 1 (A) Cognitive-habit learning (weather prediction) task performance in whole sample of patients with schizophrenia (SC) and healthy control (NC) participants $(n=35)$. (B) Cognitive-habit learning (weather prediction) task performance in matched sample of patients with schizophrenia (SC) and healthy control (NC) participants $(n=14)$. (O) Patients; $(\square)$ controls; $( \pm)$ standard error provided as measure of variance.

that the cognitive-habit difference score of patients with SC (mean $=7.3, \mathrm{SD}=18.0$ ) did not differ significantly from controls $($ mean $=11.8, \mathrm{SD}=15.0), \mathrm{t}(68)=1.13, P>0.26$. Using the Holm (1979) method for multiple testing, with a familywise error rate of 0.05 , it was found that the patients with SC performed at chance levels until trial 80 , whereas the NC participants performed at chance levels only until trial 20. Patients with SC differed from controls with respect to the number of no responses (SC mean number of no responses $=10.8, \mathrm{SD}=11.8$; $\mathrm{NC}$ mean number of no responses $=2.7, \mathrm{SD}=3.0), \mathrm{t}(68)=3.96, P<0.001$, and reaction times ( $\mathrm{SC}$ mean reaction time $=398 \mathrm{msec}, \mathrm{SD}=97$; $\mathrm{NC}$ mean reaction time $=322 \mathrm{msec}, \mathrm{SD}=54), \mathrm{t}(67)=3.95$, $P<0.001$. Determination of outliers $\geqslant 2$ SD below the mean number of no responses in each group resulted in removal of 2 patients and 3 controls. A two-way repeated measures ANOVA on the mean percent correct transformed scores of the data following exclusion of outliers displayed a main effect of group, $\mathrm{F}(1,63)=7.14, P<0.01$, a significant main effect of trial, $\mathrm{F}(14,882)=22.82$, $P<0.001$, and no significant group by trial interaction, $\mathrm{F}(14,882)=0.89, P=0.584$.

Comparison of the matched groups of patients and controls also displayed impaired overall cognitive-habit performance in patients relative to controls (Fig. 1B). A two-way repeated measures ANOVA on the mean percent correct transformed scores displayed a main effect of group, $\mathrm{F}(1,26)$ $=4.98, P<0.034$, and a significant main effect of trial, $\mathrm{F}(14,364)=12.44, P<0.001$, but no group by trial interaction, $\mathrm{F}(14,364)$ $=0.64, P=0.835$. A separate dependent $\mathrm{t}$ test revealed that the slope of the learning curve across the first 50 trials in patients with SC (mean $=1.0, \mathrm{SD}=4.4)$, did not differ significantly from the slope displayed by controls (mean $=0.7, \mathrm{SD}=3.0$ ), $\mathrm{t}(13)=0.33, P>0.75$. Cognitive-habit difference score also did not differ significantly between patients with SC (mean = 10.8, $\mathrm{SD}=16.9)$ and controls (mean $=7.0$, $\mathrm{SD}=13.0), \mathrm{t}(13)=0.84, P>0.42$. Similar to the whole sample comparison, the patients with SC performed at chance levels until trial 80, whereas the NC participants performed at chance levels only until trial 20 . Patients with SC did not differ from controls with respect to the number of no responses (SC mean number of no responses $=8.9, \mathrm{SD}$ $=9.8$; $\mathrm{NC}$ mean number of no responses $=$ $3.4, \mathrm{SD}=3.5), \mathrm{t}(13)=2.08, P>0.06$, and reaction times $(\mathrm{SC}$ mean reaction time $=385 \mathrm{msec}, \mathrm{SD}=78$; $\mathrm{NC}$ mean reaction time $=343 \mathrm{msec}, \mathrm{SD}=67), \mathrm{t}(13)=1.69$, $P>0.11$, although a trend was present with respect to the number of no responses.

Separate dependent t-tests displayed no significant difference between the matched patients and controls on an executive function test associated with frontal lobe activity, the Wisconsin Card Sort Test (WCST), mean number of categories obtained in patients was $6.1(\mathrm{SD}=3.2)$ and in controls was $7.2(\mathrm{SD}=2.8), \mathrm{t}(11)=0.72, P>0.49$, whereas mean percent of perseverative errors in patients was $14.1(\mathrm{SD}=10.7)$ and in controls was $11.7(\mathrm{SD}=5.7)$, $\mathrm{t}(11)=0.63, P>0.54$, suggesting that differences were not due to frank working memory/planning deficits.

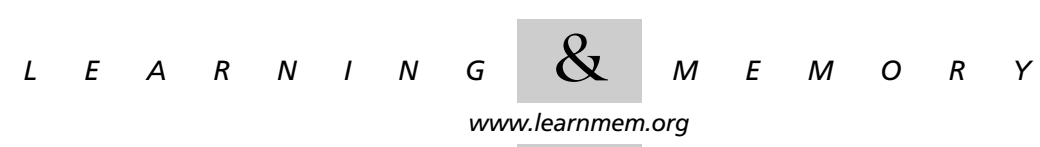




\section{Motor-skill Learning}

Comparing all patients and controls, patients with SC displayed motor-skill learning deficits across trial blocks 2-6 (Fig. 2A). A two-way repeated measures ANOVA revealed a main effect of group, $\mathrm{F}(1,68)=6.85, P<0.01$, a significant main effect of trial block, $\mathrm{F}(5,340)=62.93, P<0.001$, and a significant group by trial block interaction, $\mathrm{F}(5,340)=$ $3.14, P<0.009$, such that predetermined Least Significant Difference (LSD) post hoc analyses revealed significant differences between patients and controls at trial blocks 2, 3, 4,5 , and 6 . The slope of the line for trial blocks 1-6 was not significantly different between patients with SC $($ mean $=$ $0.28, \mathrm{SD}=0.26$ ) and $\mathrm{NC}$ participants (mean $=0.38, \mathrm{SD}=$ $0.29), \mathrm{t}(68)=1.59, P>0.12$. However, there was a significant difference between the motor-skill difference score
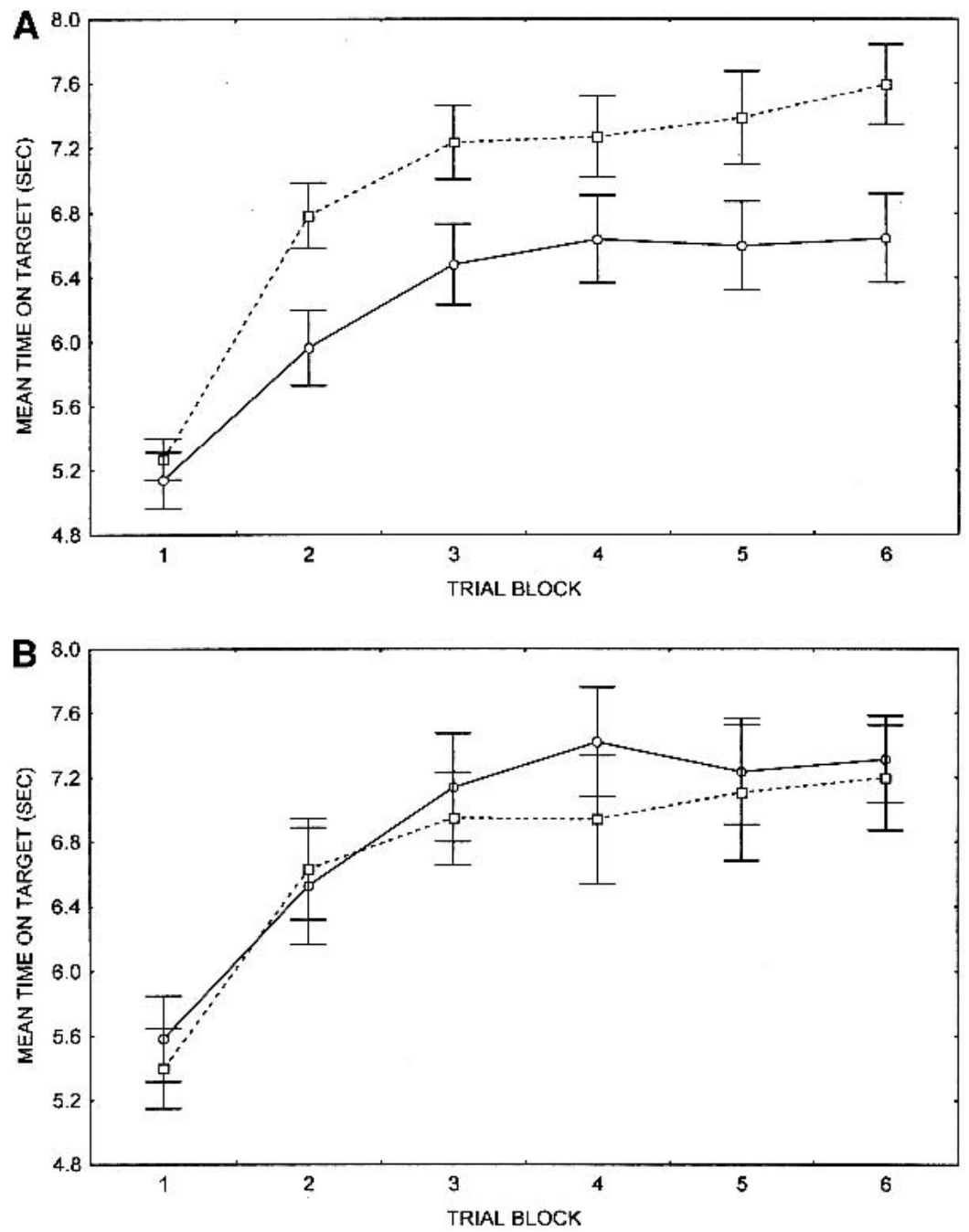

Figure 2 (A) Motor-skill learning (pursuit rotor) task performance in whole sample of patients with schizophrenia (SC) and normal control (NC) participants $(n=35)$. (B) Motor-skill learning (pursuit rotor) task performance in matched sample of patients with schizophrenia (SC) and normal control (NC) participants $(n=14)$. (O) Patients; $(\square)$ controls; $( \pm)$ standard error provided as measure of variance. (trial 6-trial 1) of patients with SC $($ mean $=1.5, \mathrm{SD}=1.4)$ and controls $($ mean $=2.3, \mathrm{SD}=1.4), \mathrm{t}(67)=2.30, P>0.02$. Using separate independent t-tests, the speed at which the rotating disk was set in order to equate performance at the beginning of the test was determined to be significantly different between patients with SC (mean $=40.3 \mathrm{rpm}, \mathrm{SD}=$ 9.6) and controls (mean $=46.7 \mathrm{rpm}, \mathrm{SD}=6.9), \mathrm{t}(68)=3.19$, $P<0.002$. Determination of outliers $\geqslant 2$ SD below the mean rpm setting in each group resulted in removal of 1 patient and no controls. A two-way repeated measures ANOVA on the mean time on target at each of six trial blocks following exclusion of outliers displayed a significant main effect of group, $\mathrm{F}(1,67)=5.80, P<0.02$, a significant main effect of trial, $\mathrm{F}(5,335)=65.57, P<0.001$, and a significant group by trial interaction, $\mathrm{F}(5,335)=2.71$, $P=0.02$.

In the matched group comparison, however, patients with SC did not differ from controls across the six trial blocks of the pursuit rotor task (Fig. 2B). This was unexpected, and suggests that differences in this task may be related to global information processing ability. A two-way repeated measures ANOVA displayed a main effect of trial block, $\mathrm{F}(5,125)=26.30, P<$ 0.001 , and no main effect of group, $\mathrm{F}(1$, $25)=0.06, P>0.80$, nor a group by trial block interaction, $\mathrm{F}(5,125)=1.02, \quad P>$ 0.41 . Separate dependent t-tests displayed no significant difference between patients with SC $($ mean $=41.3 \mathrm{rpm}, \mathrm{SD}=8.3)$ and controls $($ mean $=45.0, \mathrm{SD}=6.5$ ) with respect to the speed at which the rotating disk was set to equate performance at the beginning of the test, $\mathrm{t}(13)=1.48, P>$ 0.16 . The slope of the line for trial blocks 1-6 was not significantly different between patients with SC $($ mean $=0.34, \mathrm{SD}=0.17)$ and controls (mean $=0.30, \mathrm{SD}=0.26$ ), $\mathrm{t}(13)=0.54, P>0.60$. Additionally, the slope of the line for trial blocks 1-2 was not significantly different between patients with SC (mean $=0.95, \mathrm{SD}=0.91)$ and controls $($ mean $=1.23, \mathrm{SD}=0.97), \mathrm{t}(13)=0.97$, $P>0.35$. Likewise, the motor-skill difference score did not differ significantly between patients with $\mathrm{SC}($ mean $=1.8, \mathrm{SD}=$ $0.87)$ and controls (mean $=1.8, \mathrm{SD}=1.2)$, $\mathrm{t}(13)=0.04, P>0.97$.

\section{Correlations}

All correlations described below, with the exception of those indicated, were not significant with $P>0.05$. Performance on the

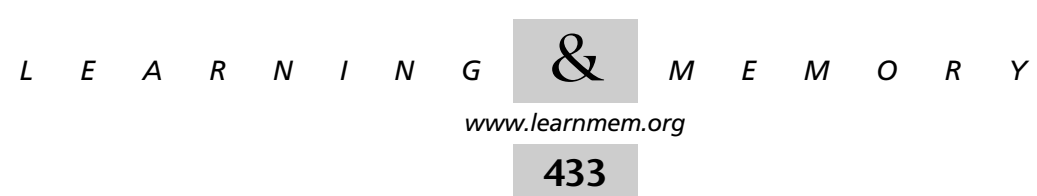


weather prediction and pursuit rotor tasks were only weakly correlated in both patients $(0.17 \geqslant r \geqslant-0.21)$ and controls $(0.21 \geqslant r \geqslant-0.30)$. Only weak correlations were obtained between the number of categories achieved on the WCST and cognitive habit-learning difference score $(r=-0.26$ in patients with SC and $r=0.11$ in NC participants), and between the number of categories achieved on the WCST and percent correct at trial 150 of the cognitivehabit learning task ( $r=0.22$ in patients with SC and $r=0.15$ in NC participants). In general, only weak correlations were obtained between reaction time and performance on the cognitive-habit learning test in patients $(0.35 \geqslant r \geqslant-0.24)$ and controls $(0.17 \geqslant r \geqslant-0.09)$, with only $r=0.35$ at trial 10 in the patients displaying significance. Additionally, only weak correlations were obtained between the number of no responses and performance on the cognitive-habit learning test in patients $(0.26 \geqslant r \geqslant-0.29)$ and controls $(0.19 \geqslant r \geqslant 0.02)$. Only weak correlations were obtained between Positive and Negative Symptom Scale (PANSS) scores and cognitive-habit learning slope and difference scores in the whole $(0.04 \geqslant r \geqslant-0.20)$ and matched patient samples $(-0.09 \geqslant r \geqslant-0.21)$. Similarly, only weak correlations were obtained between Abnormal Involuntary Movement Scale (AIMS) tardive dyskinesia (TD) scores and cognitive-habit learning slope and difference scores in the whole $(r=-0.15$ and $r=-0.17)$ and matched patient samples $(r=-0.12$ and $r=-0.19)$. Likewise, only weak correlations were obtained between AIMS Parkinsonian (PD) scores and cognitive-habit learning slope and difference scores in the whole $(r=-0.12$ and $r=-0.14)$ and matched patient samples $(r=0.01$ and $r=-0.03)$.

In general, correlation between motor-skill learning and FSIQ (for patients: $0.32 \geqslant r \geqslant 0.18$ and controls: $0.37 \geqslant r \geqslant 0.04$ ) was stronger than correlation between cognitive-habit learning and FSIQ (for patients: $0.34 \geqslant r \geqslant$ -0.28 and controls: $0.18 \geqslant r \geqslant-0.04)$ with only the difference score between trials 150 and trial 10 of the cognitivehabit learning test correlating significantly with IQ in patients $(r=0.34)$ and the mean time on target at trial block 6 during the pursuit rotor test correlating significantly with IQ in controls $(r=0.37)$. Weak correlations were obtained between FSIQ and slopes of the learning curves for both cognitive-habit learning $(r=0.36, P<0.05$ in patients with SC and $r=0.08$ in NC participants) and motor-skill learning ( $r=0.28$ in patients with SC and $r=0.34, P<0.05$ in NC participants). Only weak-to-moderate correlations were obtained between PANSS scores and motor-skill learning slope and difference scores in the whole $(0.05 \geqslant r \geqslant-0.08)$ and matched patient samples $(0.43 \geqslant r \geqslant-0.23)$. Similarly, only weak correlations were obtained between AIMS TD scores and motor-skill learning slope and difference scores in the whole $(r=-0.17$ and $r=-0.07)$ and matched patient samples $(r=0.06$ and $r=0.19)$. Significant mild-to-moderately strong correlations were obtained between AIMS PD scores and motor-skill learning slope $(r=-0.37, P=-0.03)$ and difference scores $(r=-0.40, P=0.02)$ in the whole patient sample; however, only weak, nonsignificant correlations were obtained between AIMS PD scores and motorskill learning slope $(r=0.17)$ and difference scores $(r=0.09)$ in the matched patient sample.

\section{DISCUSSION}

Patients with SC were impaired with respect to their overall performance relative to controls on a test of cognitive-habit learning. Removal of outliers with respect to the number of no responses produced identical results. Significant differences were maintained even between a subset of patients and controls matched on the potentially confounding variables of age, education, general intellectual level, and reading ability. The apparent difference between patients with SC and controls with respect to the slope across the first 30 trials in the cognitive-habit learning task (Fig. 1A) failed to attain statistical significance, probably due to the large amount of variance that typically occurs during the earlier trials of this task. Although there was a significant overall performance difference between patients with SC and controls on a test of cognitive-habit learning, the lack of a group by trial interaction and the lack of slope differences between groups would argue against a cognitive-habit learning deficit in SC. These results are largely consistent with earlier studies. Johnston and Bursill (1973) failed to obtain significant differences in probability learning between patients with SC and controls, however, they demonstrated a significant overall performance deficit in the face of preserved learning during latter trials for nonparanoid patients with SC relative to paranoid patients with SC and controls. Clare et al. (1993) obtained an overall performance deficit in the absence of learning impairment during a nondeclarative motor-skill learning study of patients with SC. Other investigators have demonstrated preserved declarative and nondeclarative learning in the face of impaired overall performance in normal aging and frontal lobe patients (Howard and Howard 1989; Mutter and Pliske 1994; Vakil and Agmon-Ashkenazi 1997; Hildebrandt et al. 1998), which has been thought to be associated with working memory or speed deficits. As mentioned previously, prior studies (Poldrack et al. 1999, 2001) have demonstrated prefrontal activation during administration of the weather prediction cognitive-habit learning test, which would allow for the possibility of impaired overall performance to be the result of prefrontal abnormalities in compromised groups. On tasks of declarative learning, such as the California Verbal Learning Test, this pattern of reduced overall performance paired with intact learning has been interpreted to represent frontal lobe dysfunction and preserved hippocampal function (Moscovitch 1992). Given the analogy between the declarative system-relying on the hippocampus and prefrontal cortex during verbal list learning, and the

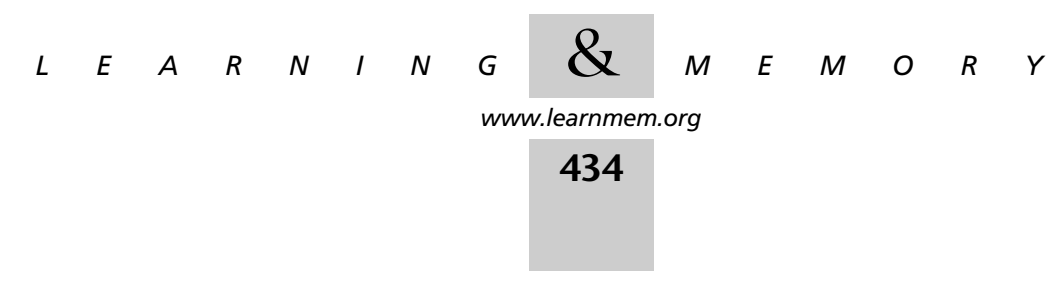


nondeclarative system-relying on the caudate and DLPFC during cognitive-habit learning, an argument for DLPFC dysfunction and caudate preservation in SC can be made on the basis of the current findings. However, our demonstration of an overall performance deficit in cognitive-habit learning along with surprisingly intact WCST and IQ performance in the matched patient group would suggest that this account may be an oversimplification. Perhaps some, but not all, regions of the DLPFC may be subtly compromised. Further studies are warranted to determine the location and nature of the DLPFC contribution to cognitive-habit learning.

With respect to cognitive-habit learning in the overall sample, both groups clearly began the cognitive-habit learning task at near chance levels. Whereas the controls improved their performance significantly above chance after 20 trials, the patients with SC took until trial 80 to perform significantly above chance levels. Because overall performance was poorer in patients relative to controls, but learning rate did not differ, the patients would be expected to rise above chance levels at a later point than controls. These differences may reflect abnormal connectivity within DLPFC associated with nondeclarative habit learning that provides altered input to the striatum, especially during early trials when the NC participants displayed the greatest improvement.

Similar to the results of the present study, Keri et al. (2000) failed to demonstrate a difference in learning between patients with SC and controls. In a departure from the results of the current study, Keri et al. (2000) did not obtain an overall performance difference between the groups. As described previously, methodological differences that altered the implicit and/or probabilistic nature of the task may have been responsible for the discrepancy between studies.

The motor-skill learning differences obtained in the overall sample are consistent with earlier evidence of impaired procedural learning in some patients with SC (Huston and Shakow 1949; Eysenck and Frith 1977; Schwartz et al. 1996). However, the findings of preserved motor-skill learning in patients matched to controls on the basis of age, education, and IQ support previous findings of preserved procedural learning in other patients with SC (Clare et al. 1993; Goldberg et al. 1993; Granholm et al. 1993; Kern et al. 1997). Elimination of outliers on the basis of rpm settings from the whole sample produced results identical to the whole-sample finding of impaired learning, suggesting that the subset of matched patients did not simply exclude fatigued patients or include only the most motivated or alert patients. Previous work has shown that ability level (Eysenck and Gray 1971) and intelligence level (Eysenck and Frith 1977) contribute to differential motor-skill learning performances in controls and in patients with schizophrenia. Also, Goldberg et al. (1993) have demonstrated correlations between pursuit rotor motor-skill learning and IQ in monozygotic twins discordant for SC. Therefore, the paradoxical motor-skill learning results between studies may be explained on the basis of differences in generalized cognitive integrity and, by inference, widespread cerebral dysfunction as assessed by IQ. Previous studies (Huston and Shakow 1949; Schwartz et al. 1996) demonstrating impaired motor-skill learning in patients with SC did not match for generalized cognitive integrity. Although Schwartz et al. (1996) used a dementia rating measure to assess neuropsychological function, a test designed to measure performance at the level of dementia might not be sensitive to small group differences within specific cognitive domains, and could also be subject to ceiling effects. Furthermore, patients in the Schwartz et al. (1996) study were not specifically matched to controls on the dementia rating variable.

Relative to the whole patient sample, improved motorskill learning ability in the subset of patients matched to controls on the basis of IQ may be due to attention differences between the whole sample and matched subset of patients, as numerous studies have demonstrated attention deficits in patients with schizophrenia (Cohen and ServanSchreiber 1992; Mirsky et al. 1992; Palmer et al. 1997; Weickert et al. 2000) and measures of attention, such as the Continuous Performance Test, show a consistent relationship with IQ and academic achievement (Ballard 1996). However, this rarefied subset of matched patients displayed increases on virtually all measures of tests we routinely administer to all patients assessing cognitive domains of attention, executive function, memory, language, and visual spatial perception (data available upon request). Therefore, rather than any one aspect of general intellect contributing to improved motor-skill learning in the matched patient group, it would appear as though a general improvement across all cognitive domains may produce the motor-skill improvement.

As shown in Table 1, both impaired and unimpaired motor-skill learning has been demonstrated in patients with SC using (1) versions of the pursuit rotor that require handheld wand to rotating disk physical contact and those that require contact with a photoelectric cell maintained in the hand-held wand, (2) small to moderately large numbers of patients and controls, and (3) fixed revolutions per minute (rpm) of the rotating disk and rpm adjusted for differential motor ability to equate initial performance between groups. For those studies in Table 1 examining motor-skill learning with the pursuit rotor test, current IQ data was either not collected or was not used as a matching variable between patients and controls. Although Clare et al. (1993) matched on an estimate of premorbid IQ, National Adult Reading Test, previous studies have shown that patients with SC often display significant declines from premorbid IQ levels (Lubin et al. 1962; Schwartzman and Douglas 1962; Dalby

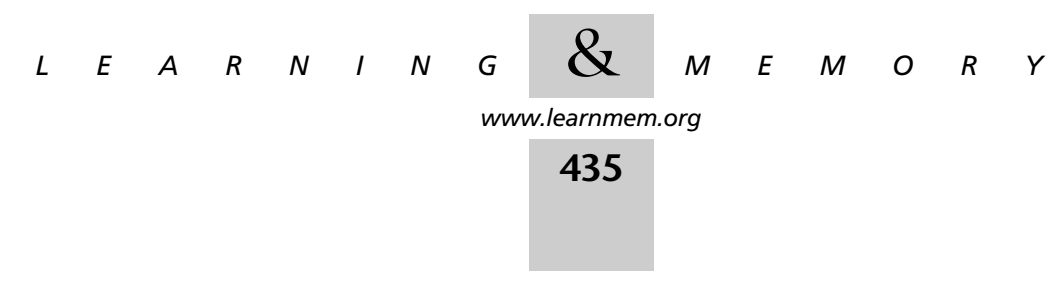


Table 1. Summary of Motor-Skill Learning Studies Using the Pursuit Rotor Task in Patients with Schizophrenia

\begin{tabular}{|c|c|c|c|c|c|c|}
\hline & $\begin{array}{l}\text { Huston and } \\
\text { Shakow } \\
\text { (1949) }\end{array}$ & $\begin{array}{c}\text { Goldberg et al. } \\
\text { (1993) }\end{array}$ & $\begin{array}{c}\text { Granholm et al. } \\
\text { (1993) }\end{array}$ & $\begin{array}{c}\text { Clare et al. } \\
\text { (1993) }\end{array}$ & $\begin{array}{c}\text { Schwartz et al. } \\
\text { (1996) }\end{array}$ & $\begin{array}{c}\text { Kern et al. } \\
\text { (1997) }\end{array}$ \\
\hline version & contact & contact & photoelectric & not specified & contact & photoelectric \\
\hline Design & $\begin{array}{l}2 \text { blocks of } \\
5-10 \text {-sec trials }\end{array}$ & $\begin{array}{l}3 \text { blocks of } \\
5-20-\sec \text { trials }\end{array}$ & $\begin{array}{l}6 \text { blocks of } \\
4-20-\text { sec trials }\end{array}$ & $\begin{array}{l}5 \text { blocks of } \\
6-20-\text { sec trials }\end{array}$ & $\begin{array}{l}6 \text { blocks of } \\
4-20-\text { sec trials }\end{array}$ & $\begin{array}{l}6 \text { blocks of } \\
4-20 \text {-sec trials }\end{array}$ \\
\hline N & $\begin{array}{l}\mathrm{SC}=122 \\
\mathrm{NC}=60\end{array}$ & $\begin{array}{l}24 \text { discordant } \\
\text { and } 7 \text { normal } \\
\text { twin pairs }\end{array}$ & $\begin{array}{l}\mathrm{SC} / \mathrm{TD}+=7 \\
\mathrm{SC} / \mathrm{TD}-=4 \\
\mathrm{NC}=11\end{array}$ & $\begin{array}{l}\mathrm{SC}=11 \\
\mathrm{NC}=12\end{array}$ & $\begin{array}{l}\text { elderly } S C=20 \\
\text { elderly } N C=20 \\
\text { young } S C=20 \\
\text { young } N C=20\end{array}$ & $\begin{array}{l}\mathrm{SC}=18 \\
\mathrm{NC}=15\end{array}$ \\
\hline RPM & 60 & 30 and 60 & 45 & 30 & $\begin{array}{l}\text { elderly SC } 40.50 \\
\text { elderly NC } 48.75 \\
\text { young SC } 47.25 \\
\text { young NC } 56.25\end{array}$ & $\begin{array}{l}\mathrm{SC}=37.2 \\
\mathrm{NC}=62.7\end{array}$ \\
\hline Trial 1 matched? & No & No & No & No & Yes & Yes \\
\hline IQ matched? & No & No & No & No & No & No \\
\hline Overall difference? & $\mathrm{SC}<\mathrm{NC}$ & $\mathrm{SC}=\mathrm{NC}$ & $\mathrm{SC}=\mathrm{NC}$ & $\mathrm{SC}<\mathrm{NC}$ & $\mathrm{SC}<\mathrm{NC}$ & $\mathrm{SC}=\mathrm{NC}$ \\
\hline Slope difference? & not specified & not specified & $\mathrm{SC}=\mathrm{NC}$ & $\mathrm{SC}=\mathrm{NC}$ & $\mathrm{SC}<\mathrm{NC}$ & not specified \\
\hline
\end{tabular}

(SC) Patients with schizophrenia; (NC) normal control participants; (SC/TD+) patients with schizophrenia and tardive dyskinesia; (SC/TD-) patients with schizophrenia without tardive dyskinesia.

and Williams 1986; Nelson et al. 1990; Kremen et al. 1996). Other task parameters, such as neuroleptic administration and apparatus differences, remain as possible explanations; however, no factor other than widespread cortical processing appears to consistently account for the contradictory results across studies. Because performance on the pursuit rotor task is believed to rely in part on the putamen, findings of equivalent performance between matched patients and controls in the present study is consistent with the hypothesis of putamen preservation in intellectually intact patients with SC.

Several potential confounds (neuroleptic medication class, motor abnormalities, psychotic symptom severity, diagnostic subtype, and gender ratio) could account for the loss of a significant motor-skill learning difference in the matched group comparison. Comparisons of cognitive-habit and motor-skill learning on the basis of neuroleptic class (typical vs. atypical) were not performed due to the small number of patients receiving typical neuroleptic medication $(n=4)$. However, the proportions of patients receiving each of the various neuroleptic and adjunctive medications were approximately equivalent in the whole sample and matched group. The mean AIMS PD and TD scores and standard deviations between the whole patient sample and the matched patient group were strikingly similar and generally yielded weak correlations with cognitive-habit and motor-skill learning. Similarly, the mean PANSS scores and standard deviations between the whole patient sample and the matched patient group were remarkably similar. In general, only weak correlations were obtained between cognitive-habit learning and symptom severity, whereas weak to moderately strong correlations were obtained between motor-skill learning and symptom severity ratings. With respect to diagnostic subtype, there was no significant difference among diagnostic subtypes for either cognitive-habit or motor-skill learning (data available upon request). The rather large relative improvement in learning displayed in the matched patient group, which remained consistent to the whole patient sample with respect to gender ratio, would be more likely to account for the loss of a significant learning difference in the matched group comparison than the minor suppression of learning displayed by the matched control group with an altered gender ratio. Furthermore, there was no significant difference between male and female controls or patients with respect to time on target at each of the six trial blocks (data available upon request). Therefore, none of the potential confounds listed above would appear to contribute to the loss of significant learning in the matched group comparison.

An important caveat with respect to the results of the present study pertains to the effect of antipsychotic medication. Because the present study and the majority of previous studies [with the possible exception of Huston and Shakow (1949)] assessed patients receiving neuroleptic medication, the effect of antipsychotic medication upon skill learning in SC remains an open question and should be the focus of future studies. It is conceivable that the beneficial effects of striatal dopamine D2 receptor blockade may normalize skill learning in patients with SC to some degree. An additional caveat pertains to the generalizability of the current findings to all patients with SC. Whereas the matched NC group displayed relatively little Wechsler Adult

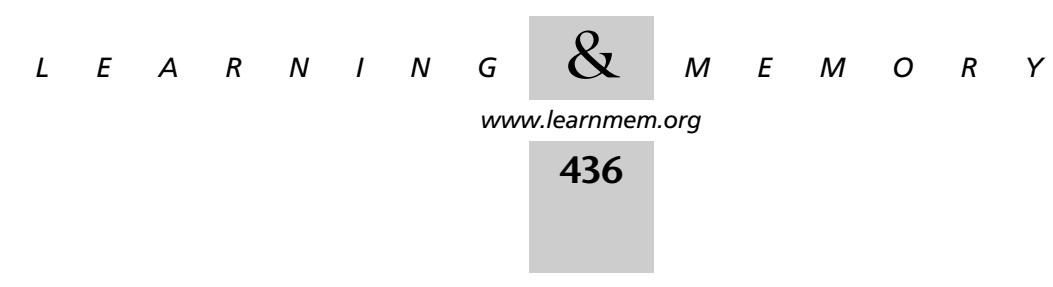


Intelligence Scale-Revised (WAIS-R) FSIQ difference from the whole NC sample with a mean increase of 1.2 points in the matched NC group, relative to the whole patient sample the subset of matched patients with SC displayed a WIAS-R FSIQ mean increase of 3.5 points. This would suggest that although the matched NC group remained relatively consistent with the whole NC sample, the matched patient group reflects a bias toward patients displaying less severe cognitive deficits. Although this sampling bias in the subset of matched patients appears to significantly improve motorskill learning ability as noted above, it did not appear to alter cognitive-habit learning, as the results of the subset of matched patients were identical to the whole patient sample.

In summary, by obtaining overall performance deficits in the presence of normal learning rate in patients with SC on a test of cognitive-habit learning, the current results are most consistent with normal striatal processing that receives abnormal input via cerebral cortex (e.g., DLPFC) in SC. Future studies will be needed to further specify the nature of the relationship between caudate and DLPFC activation during cognitive-habit learning in both medicated and nonmedicated patients. Additionally, motor-skill learning impairment in patients differing in IQ from controls relative to preserved motor-skill learning suggests (1) that generalized abnormalities influence motor-skill learning and (2) that putamen function can be preserved in intellectually intact patients with SC at least as it applies to motorskill learning.

\section{MATERIALS AND METHODS}

\section{Participants}

A total of 35 patients, 28 males and 7 females, (32 right-hand dominant) with a diagnosis of SC (11 inpatients and 24 outpatients) participated in this study. Two board-certified psychiatrists concurred on diagnosis by Structured Clinical Interview for the Diagnostic and Statistical Manual fourth edition, without knowledge of neuropsychological performance. The frequency of diagnostic subtypes for these 35 patients was as follows: 12 undifferentiated, 9 paranoid, 4 schizoaffective, 2 chronic, 4 disorganized, 1 schizotypical, 2 residual, and 1 simple. Patients who received concurrent axis I psychiatric diagnoses other than SC, or having a history of current substance abuse, head injuries with concomitant loss of consciousness, seizures, central nervous system infection, diabetes, or hypertension were excluded. Patients were all receiving doses of antipsychotic medication at the time of testing with the majority (86\%) receiving atypical neuroleptics such as olanzapine and risperidone. In addition to patients with SC, $35 \mathrm{NC}$ participants, 17 males and 18 females (30 right-hand dominant) recruited through the National Institutes of Health normal volunteer office, participated in this study. NC participants with a history of psychiatric disorders, current substance abuse, head injuries with concomitant loss of consciousness, seizures, central nervous system infection, diabetes, or hypertension were excluded. All participants provided informed written consent prior to participation in this study. The Institutional Review Board of the National Institute of Mental Health provided approval for this study.

\section{Measures of General Cognitive Abilities and Executive Function}

A four-subsection version of the WAIS-R and the Reading subsection of the Wide Range Achievement Test-Revised (WRAT-R) was administered to all subjects in order to obtain an estimate of current Full Scale Intelligence Quotient (FSIQ) and premorbid intellectual ability in patients, respectively. The Reading subsection of the WRAT-R has been demonstrated to be an indicator of premorbid intellectual abilities in previous studies (Nelson and McKenna 1975; Nelson and O'Connell 1978; Dalby and Williams 1986; Nelson et al. 1990; Frith et al. 1991; Kremen et al. 1996). The four-subsection version of the WAIS-R used to obtain estimated FSIQ was composed of Arithmetic, Similarities, Picture Completion, and Digit Symbol Substitution subsections (Missar et al. 1994). Additionally, the Wisconsin Card Sorting Test (WCST) was administered to a subset of 14 patients and 14 matched controls as a test of Executive function (Milner 1963).

\section{Assessment of Psychotic Symptoms and Motor Abnormalities}

Psychotic symptom severity was assessed weekly using the Positive and Negative Symptom Scale (PANSS) (Kay et al. 1987) by members of the nursing staff trained in the administration and scoring of the PANSS. The assessment closest to the cognitive-habit and motorskill testing dates was used to obtain indices of positive and negative symptoms, general, and total scale scores. Motor abnormalities, such as extrapyramidal symptoms and tardive dyskinesia, that may develop as side effects of administration of antipsychotic medication, were assessed using the Abnormal Involuntary Movement Scale (AIMS) PD and TD rating scales (Fann et al. 1977; Smith et al. 1978), respectively, by a board-certified neurologist trained in administration and scoring of the AIMS. Assessments were obtained within one day of cognitive-habit and motor-skill testing. Correlation of PANSS and AIMS ratings with motor-skill learning scores was performed to determine possible relationships among motorskill learning and psychotic symptoms or motor abnormalities.

\section{Demographics, General Cognitive Abilities, Psychotic Symptoms, and Motor Ratings}

See Table 2 for a summary of the mean age, education level, current WAIS-R estimated FSIQ level, and WRAT-R Reading standard scores for patients and controls. Separate independent t-tests revealed no difference between patients and controls with respect to age, $\mathrm{t}(68)=0.01, P=0.99$. However, there were significant differences between the groups on the basis of years of education, $\mathrm{t}(68)=4.05$, $P<0.001$, WAIS-R estimated FSIQ, $\mathrm{t}(67)=5.25, P<0.001$, and WRAT-R Reading Standard scores, $\mathrm{t}(68)=3.50, P<0.001$. Therefore, in addition to analyses comparing the entire sample of patients and controls, subsequent analyses will include comparisons between a subset of 14 patients (13 were right-hand dominant, 9 were male, and 4 were inpatients) matched by TWW to within $5 \mathrm{yr}$ of age and education, and within 5 points on WAIS-R FSIQ estimate and WRAT-R Reading Standard scores of 14 controls (12 right-hand dominant, 5 males and 9 females). Matching was limited to 14 patients and controls due to the relatively large number of matched variables (4) and the limited number of patients and controls (35). The frequency of diagnostic subtypes for the 14 matched patients was as follows: 4 undifferentiated, 2 paranoid, 4 schizoaffective, 1 chronic, 2 disorganized, and 1 schizotypical. Seventy-nine percent of the patients from the matched sample were receiving atypical

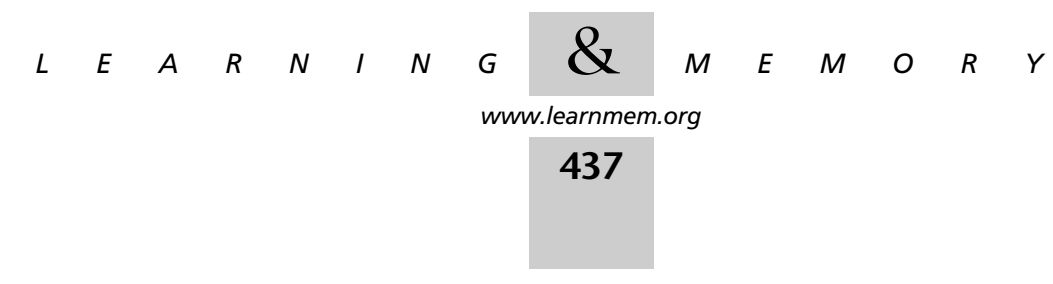


Table 2. Mean Age, Education Level, and IQ Scores for Patients with SC and NC Participants

\begin{tabular}{|c|c|c|c|c|c|}
\hline & $\mathrm{N}$ & Age & $\begin{array}{l}\text { Education } \\
\text { (years) }\end{array}$ & $\begin{array}{l}\text { Wechsler adult intelligence } \\
\text { scale-revised estimated full scale IQ }\end{array}$ & $\begin{array}{l}\text { Wide range achievement } \\
\text { test-revised reading standard score }\end{array}$ \\
\hline \multicolumn{6}{|l|}{ Overall sample } \\
\hline Patients with schizophrenia & 35 & $35.0(8.2)$ & $14.0 *(2.0)$ & $91.9 *(12.9)$ & $102.4 *(11.5)$ \\
\hline Normal control participants & 35 & $35.0(10.3)$ & $15.8(1.8)$ & $106.6(10.0)$ & $110.3(6.8)$ \\
\hline \multicolumn{6}{|l|}{ Matched sample } \\
\hline Patients with schizophrenia & 14 & $38.6(8.9)$ & 14.9 (1.9) & $103.4(8.2)$ & $110.1(8.1)$ \\
\hline Normal control participants & 14 & $36.9(8.4)$ & $15.2(1.8)$ & $107.4(7.4)$ & $108.3(8.9)$ \\
\hline
\end{tabular}

Standard deviation in parentheses. Matched sample matched on the basis of age, education, Wechsler Adult Intelligence Scale-Revised estimated Full-Scale IQ scores and Wide Range Achievement Test-Revised Reading standard scores.

*Denotes statistically significant difference from Normal Control participants at $P<.001$.

neuroleptic medication. See Table 2 for the mean age, education level, current WAIS-R estimated FSIQ level, and WRAT-R Reading standard scores of the matched patient and control groups. Separate dependent t-tests applied to these matched group data revealed no significant differences between these matched groups of patients and controls with respect to age, $\mathrm{t}(13)=0.48, P<0.64$, education, $\mathrm{t}(13)=0.64, \quad P>0.54$, WAIS-R estimated FSIQ, $\mathrm{t}(13)=1.54, P>0.15$, and WRAT-R Reading standard scores, $\mathrm{t}(13)=0.54, P>0.60$. See Table 3 for a listing of the medications and dosage ranges administered during cognitive-habit and motorskill assessments in patients from the whole and matched samples. Medication regime and dosage range was generally consistent be- tween whole and matched patient samples with the patients in the matched sample typically being on higher doses of medication, with the exception of those patients receiving clozapine.

Patients from the whole sample displayed mean PANSS scores of 13.8 ( $\mathrm{SD}=5.0$ ) for positive symptoms, $18.0(\mathrm{SD}=7.8)$ for negative symptoms, $25.5(\mathrm{SD}=7.5$ ) for general symptoms, and 57.3 $(\mathrm{SD}=14.5)$ for a total score. The subset of patients matched to controls displayed mean PANSS scores of $14.2(\mathrm{SD}=4.0)$ for positive symptoms, $17.3(\mathrm{SD}=6.6)$ for negative symptoms, $25.9(\mathrm{SD}=$ 6.9) for general symptoms, and $57.3(\mathrm{SD}=13.4)$ for a total score. With respect to motor abnormalities, patients from the whole sample displayed mean AIMS ratings of $4.4(\mathrm{SD}=2.6)$ for Parkin-

Table 3. Medications Administered and Daily Within Group Dose Range During Testing

\begin{tabular}{|c|c|c|c|c|}
\hline Antipsychotic & Whole sample N & Dose (mg) & Matched group $\mathrm{N}$ & Dose (mg) \\
\hline olanzapine & 16 & $5-40$ & 07 & $10-40$ \\
\hline clozapine & 08 & $100-750$ & 02 & $200-300$ \\
\hline risperidone & 09 & $2-8$ & 02 & 6-8 \\
\hline quetiapine fumarate & 01 & 400 & - & - \\
\hline loxapine & 02 & $50-150$ & 01 & 150 \\
\hline fluphenazine $\mathrm{HCl}$ & 01 & 37.5 & 01 & 37.5 \\
\hline heloperidol & 03 & $10-15$ & 01 & 15 \\
\hline thioridazine & 01 & 50 & - & - \\
\hline trifluoperazine $\mathrm{HCl}$ & 02 & $5-10$ & 01 & 10 \\
\hline \multicolumn{5}{|l|}{ Ancillary medication } \\
\hline lithium & 04 & $300-900$ & 02 & 900 \\
\hline divalproex $\mathrm{Na}$ & 11 & $350-1500$ & 04 & $350-1500$ \\
\hline fluoxetine $\mathrm{HCl}$ & 02 & 20 & 01 & 20 \\
\hline sertraline $\mathrm{HCl}$ & 03 & 50-100 & - & - \\
\hline benztropine mesylate & 10 & $1-4$ & 06 & $1-4$ \\
\hline lorazepam & 07 & $1-3$ & 02 & $2-3$ \\
\hline bupropion $\mathrm{HCl}$ & 02 & $75-300$ & 01 & 300 \\
\hline gabapentin & 02 & 1200 & 01 & 1200 \\
\hline zolpidem & 02 & $5-10$ & 02 & $5-10$ \\
\hline phenytoin & 01 & 300 & - & - \\
\hline trihexyphenidyl HCl & 01 & 2 & - & - \\
\hline buspirone & 01 & 45 & 01 & 45 \\
\hline venlafaxine & 01 & 37.5 & - & - \\
\hline levothyroxine $\mathrm{Na}$ & 01 & 1 & 01 & 1 \\
\hline
\end{tabular}

The sum of numbers for whole and matched groups are greater than respective group totals, as some patients were receiving poly drug therapy. Dose refers to daily dose range for all patients comprising each group.

\section{$\begin{array}{lllllllllllllll}L & E & A & R & N & I & N & G & \& & M & E & M & O & R & Y \\ \text { www.learnmem.org } & & & & \end{array}$}


sonian symptoms and $1.2(\mathrm{SD}=1.8)$ for tardive dyskinesia. The subset of patients matched to controls displayed mean AIMS ratings of $4.1(\mathrm{SD}=2.6)$ for Parkinsonian symptoms and $0.8(\mathrm{SD}=1.2)$ for tardive dyskinesia.

\section{Cognitive-habit Learning Task}

The procedure for the weather-prediction task followed the specifications of Knowlton et al. (1996a,b). Participants were instructed that they would pretend to be a weather forecaster and that they should make a decision to predict either rain or shine on the basis of four cue cards that would be presented either individually or in combinations of up to three cards. They were also informed that they would be guessing at first but gradually they would improve at determining which cue card combinations predicted rain or shine. Cues appeared on the computer screen for $5 \mathrm{sec}$ at the beginning of each trial. Participants responded by using the mouse to position the cursor over one of two buttons marked rain or shine that were placed $1 \mathrm{~cm}$ apart on the computer screen and then clicked on the button to indicate their choice (see Fig. 3 for screen layout). When a correct response was made, the word "correct" and a smiling face appeared on the screen and a horizontal scoring bar labeled "hits," originally set at zero, increased by one unit. When an incorrect response was made, the word "incorrect" and a frowning face appeared on the screen and a second horizontal scoring bar labeled "misses," also originally set at zero, increased by one unit. Additionally, the correct response, indicated by the phrase: "You should have responded. .." along with a sun or rain diagram appeared on the screen for $2 \mathrm{sec}$. The intertrial interval was set at $0.5 \mathrm{sec}$. A prompt: "Please respond now" appeared if no response was made after the cues were displayed for $3 \mathrm{sec}$. If no response occurred 5 sec after the cues were displayed, the trial was terminated and the correct response was displayed for $2 \mathrm{sec}$. Missed trials were not included in the scoring. A total of 150 trials were completed with 1-min breaks provided following trials 50 and 100 .

This cognitive-habit learning task is a probabilistic learning task in which associations are learned gradually and presumably without conscious awareness. In this task, participants learn the relationship between two equally occurring outcome variables (rain or shine) and combinations of four cue cards each composed of simple geometric shapes (squares, triangles, circles, and diamonds) (Fig. 3). The relationship between the cue cards and the
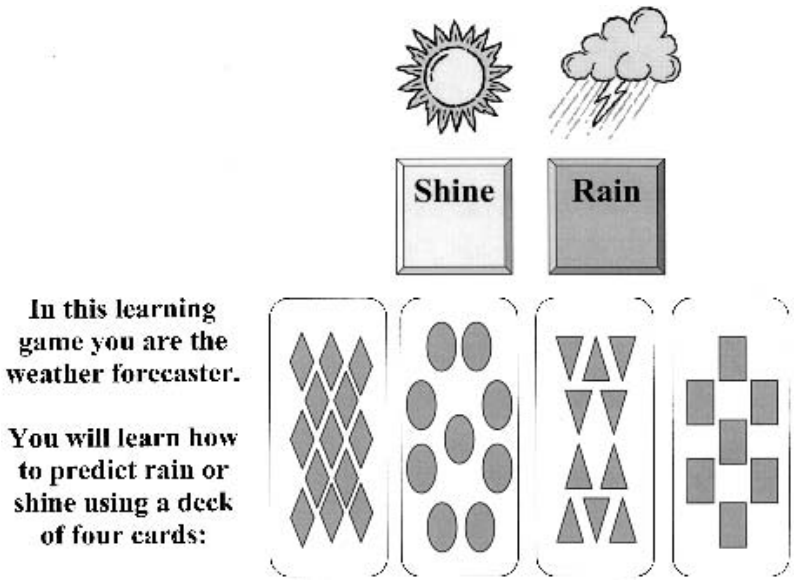

Figure 3 Screen layout for the cognitive-habit learning (weather prediction) task. outcome variables was predetermined in a probabilistic fashion (see Table 4 for the probability of obtaining outcome 1 given the various cue card combinations). Combinations of between one and three cue cards appeared on each trial randomized with the constraint that the identical cue combinations would not appear consecutively and each outcome was limited to five consecutive occurrences. The test was presented on a laptop computer with an external mouse.

\section{Cognitive-habit Learning Task Data Analysis}

Scoring followed the guidelines of Knowlton et al. (1996a,b). Responses were indicated to be correct for any given trial if the outcome selected was the outcome that was more strongly associated with the cue combination appearing on that trial (Table 4). Cue combinations were sometimes followed by less strongly associated outcomes due to the probabilistic design. Therefore, some responses were scored as correct when the feedback provided suggested that the response was incorrect. By using the percent correct score, a measure was obtained for learning of the cueoutcome associations. Mean percent correct scores were submitted to an angular transformation in order to perform statistical analyses. Chance performance was equal to a score of $50 \%$ correct, because the two outcomes occurred equally. For those trials in which the two outcomes were equally associated with the cue combination (representing $12 \%$ of all trials), the data were not analyzed, as there was no correct answer. Patient and control transformed scores for cumulative percent correct at every tenth trial were analyzed using a two-way repeated-measures ANOVA. In keeping with the Knowlton et al. (1996a,b) analysis, the slope was analyzed to determine significant linear trends. The cognitive-habit difference score between percent correct at the first and last trials was determined to provide an additional measure of learning relatively insensitive to absolute performance. In analogous fashion to that of the Knowl-

Table 4. Probability Structure of Cognitive-habit Learning (Weather Prediction) Task

\begin{tabular}{|c|c|c|c|c|c|c|}
\hline \multirow{2}{*}{$\begin{array}{l}\text { Cue } \\
\text { pattern }\end{array}$} & \multicolumn{4}{|c|}{ Cue } & \multirow{2}{*}{$\begin{array}{c}\mathrm{P} \text { (cue } \\
\text { combination) }\end{array}$} & \multirow{2}{*}{$\begin{array}{c}\mathrm{P} \\
\text { (outcome) }\end{array}$} \\
\hline & 1 & 2 & 3 & 4 & & \\
\hline 1 & 0 & 0 & 0 & 1 & .133 & .150 \\
\hline 2 & 0 & 0 & 1 & 0 & .087 & .385 \\
\hline 3 & 0 & 0 & 1 & 1 & .080 & .083 \\
\hline 4 & 0 & 1 & 0 & 0 & .087 & .615 \\
\hline 5 & 0 & 1 & 0 & 1 & .067 & .200 \\
\hline 6 & 0 & 1 & 1 & 0 & .040 & .500 \\
\hline 7 & 0 & 1 & 1 & 1 & .047 & .143 \\
\hline 8 & 1 & 0 & 0 & 0 & .133 & .850 \\
\hline 9 & 1 & 0 & 0 & 1 & .067 & .500 \\
\hline 10 & 1 & 0 & 1 & 0 & .067 & .800 \\
\hline 11 & 1 & 0 & 1 & 1 & .033 & .400 \\
\hline 12 & 1 & 1 & 0 & 0 & .080 & .917 \\
\hline 13 & 1 & 1 & 0 & 1 & .033 & .600 \\
\hline 14 & 1 & 1 & 1 & 0 & .047 & .857 \\
\hline
\end{tabular}

For any given trial, 1 of the 14 possible cue pattern combinations displayed above appeared on the computer screen with a probability indicated as: $\mathrm{P}$ (cue combination). As shown above, the probability of the cue combinations to predict sunshine (outcome 1 ) was set at $\mathrm{P}$ (outcome). Conversely, the probability of the above cue combinations to predict rain (or outcome 2) was equal to $1-\mathrm{P}$. 
ton et al. (1996a,b) study, each group's performance was compared relative to chance using the Holm (1979) method for multiple testing, with a family-wise error rate of 0.05 . Additionally, separate t-tests were used to determine group differences with respect to trials on which no responses were made and reaction time for each trial. Correlation between a measure of prefrontal function (WCST) and cognitive-habit learning was performed to ascertain possible relationships between the brain regions thought to be responsible for performance on these measures. Additionally, correlation of cognitive-habit learning with the number of no responses and reaction time were performed to detect possible relationships between performance during cognitive-habit learning and measures associated with motor ability, attention, and motivation.

\section{Motor-skill Learning Task}

The Pursuit Rotor Test (Lafayette Instruments, Model 30014) was administered to all subjects immediately following the administration of the weather prediction task described above. In this version of the pursuit rotor, the participant is required to track the motion of light that shines through a space in a rotating disk by maintaining contact between the tip of a curved light-sensor wand and the light shining through the disk. The outcome variable was time on target (in seconds). All participants were instructed to use their dominant hand (91\% of patients with SC and $86 \%$ of the NC participants were right-hand dominant). The task was divided into 6 trial blocks each consisting of five 20-sec trials with 10-sec intertrial intervals. Intervals between blocks of trials lasted $\sim 5 \mathrm{~min}$. In an attempt to control for differences in motor ability between patients with SC and NC participants, so that differences in performance would reflect differences in skill acquisition (i.e., rate of learning or slope) rather than differences in motor abilities (that may be differentially affected in SC), initial performance was equated between groups by setting the speed of disk rotation such that all participants began the task at an optimum time on target of $\sim 5 \mathrm{sec}$. This was achieved by providing an initial three-trial period during which disk rotation speed was adjusted. The pursuit rotor test provides a measure of nondeclarative motor-skill learning such that time on target gradually improves without conscious awareness of the learning process.

\section{Motor-skill Learning Task Data Analysis}

Time on target (in seconds) was recorded for each trial and the mean time on target was obtained for each block of five trials. Patient and control mean time on target scores for each of the six trial blocks were analyzed using a two-way repeated measures ANOVA. Additionally, mean time on target for each of the trial blocks was plotted and the slope of the group curves were analyzed to determine significant differences in linear trends between groups. The motor-skill difference score between mean time on target during the first and last trial blocks was determined to provide an additional measure of learning relatively insensitive to absolute performance. Independent t-tests were used to analyze group differences with respect to the speed at which the rotating disk was set to equate initial group performance. Correlation between motor-skill and cognitive-habit learning was performed to determine the possible relationship between the brain regions believed to be responsible for performance on these measures. Correlation between measures of motor-skill learning, cognitive-habit learning, and IQ were performed to ascertain the possible relationship between general intellectual ability and these measures of skill and habit learning.

\section{ACKNOWLEDGMENTS}

The publication costs of this article were defrayed in part by payment of page charges. This article must therefore be hereby marked "advertisement" in accordance with 18 USC section 1734 solely to indicate this fact.

\section{REFERENCES}

Alexander, G.E., DeLong, M.R., and Strick, P.L. 1986. Parallel organization of functionally segregated circuits linking basal ganglia and cortex. Annu. Rev. Neurosci. 9: 357-381.

Aosaki, T., Graybiel, A.M., and Kimura, M. 1994. Effect of the nigrostriatal dopamine system on acquired neural responses in the striatum of behaving monkeys. Science 265: 412-415.

Bailey, C.H. and Kandel, E.R. 1997. Molecular and structural mechanisms underlying long-term memory. MIT, Cambridge, MA

Ballard, J. 1996. Computerized assessment of sustained attention: A review of factors affecting vigilance performance. J. Clin. Exper. Neuropsychol. 18: 843-863.

Bechara, A., Tranel, D., Damasio, H., Adolphs, R., Rockland, C., and Damasio, A.R. 1995. Double dissociation of conditioning and declarative knowledge relative to the amygdala and hippocampus in humans. Science 269: 1115-1118.

Bertolino, A., Knable, M.B., Saunders, R.C., Callicott, J.H., Kolachana, B. Mattay, V.S., Bachevalier, J., Frank, J.A., Egan, M., and Weinberger, D.R. 1999. The relationship between dorsolateral prefrontal $\mathrm{N}$-acetylaspartate measures and striatal dopamine activity in schizophrenia. Biol. Psychiatry 45: 660-607.

Bertolino, A., Esposito, G., Callicott, J.H., Mattay, V.S., VanHorn, J.D., Frank, J.A., Berman, K.F., and Weinberger, D.R. 2000. Specific relationship between prefrontal neuronal $\mathrm{N}$-acetylaspartate and activation of the working memory cortical network in schizophrenia. Am. J. Psychiatry 157: 26-33.

Bustini, M., Stratta, P., Daneluzzo, E., Pollice, R., Prosperini, P., and Rossi, A. 1999. Tower of Hanoi and WCST performance in schizophrenia: Problem-solving capacity and clinical correlates. J. Psychiatr. Res. 33: 285-290

Butters, N., Wolfe, J., Martone, M., Granholm, E., and Cermak, L.S. 1985. Memory disorders associated with Huntington's disease: Verbal recall, verbal recognition and procedural memory. Neuropsychologia 23: 729-743.

Callicott, J.H., Mattay, V.S., Bertolino, A., Finn, K., Coppola, R., Frank, J.A., Goldberg, T.E., and Weinberger, D.R. 1999. Physiological characteristics of capacity constraints in working memory as revealed by functional MRI. Cereb. Cortex 9: 20-26.

Callicott, J.H., Bertolino, A., Mattay, V.S., Langheim, F.J., Duyn, J., Coppola, R., Goldberg, T.E., and Weinberger, D.R. 2000. Physiological dysfunction of the dorsolateral prefrontal cortex in schizophrenia revisited. Cereb. Cortex 10: 1078-1092.

Clare, L., McKenna, P.J., Mortimer, A.M., and Baddeley, A.D. 1993. Memory in schizophrenia: What is impaired and what is preserved? Neuropsychologia 31: 1225-1241.

Cohen, J. and Servan-Schreiber, D. 1992. Context, cortex and dopamine: A connectionist approach to behavior and biology in schizophrenia. Psychol. Rev. 99: 45-77.

Cohen, N.J. and Squire, L.R. 1980. Preserved learning and retention of pattern-analyzing skill in amnesia: Dissociation of knowing how and knowing that. Science 210: 207-210.

Cole, J.O., Klerman, G.L., Goldberg, S.C., Clyde, D.J., Davidson, E.M., Kayce, M.M., Jackson, J.R., Sullivan, P., Raskin, A., Levy, B., et al. 1964. Phenothiazine treatment in acute schizophrenia. Arch. Gen. Psychiatry 10: 246-261.

Cross, A.J., Crow, T.J., and Owen, F. 1981. 3H-Flupenthixol binding in post-mortem brains of schizophrenics: Evidence for a selective increase in dopamine D2 receptors. Psychopharmacology 74: $122-124$.

Crow, T.J. and Gillbe, C. 1974. Brain dopamine and behaviour. A critical

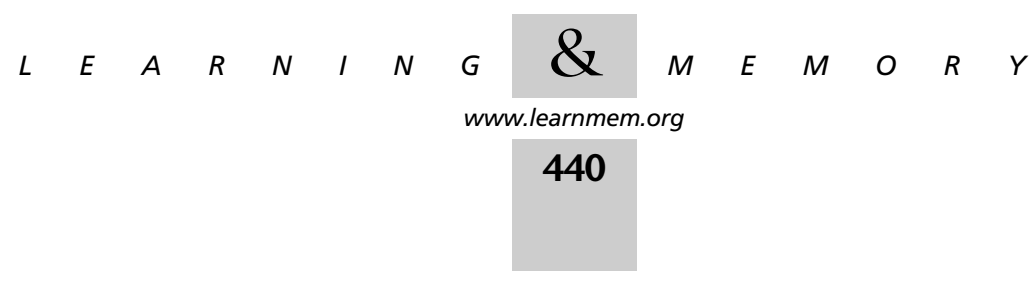


analysis of the relationship between dopamine antagonism and therapeutic efficacy of neuroleptic drugs. J. Psychiatr. Res. 11: $163-172$.

Dalby, J.T. and Williams, R. 1986. Preserved reading and spelling ability in psychotic disorders. Psychol. Med. 16: 171-175.

Divac, I., Rosvold, H.E., and Szwarcbart, M.K. 1967. Behavioral effects of selective ablation of the caudate nucleus. J. Comp. Physiol. Psychol. 63: $184-190$

Eysenck, H.J. and Gray, J.E. 1971. Reminiscence and the shape of the learning curve as a function of Subjects' ability level on the pursuit rotor. Br. J. Psychol. 62: 199-215.

Eysenck, H.J. and Frith, C.D. 1977. Reminiscence, motivation, and personality: A case study in experimental psychology. Plenum, New York, NY.

Fann, W., Stafford, J., Malone, R., Frost, J.J., and Richman, B. 1977. Clinical research techniques in tardive dyskinesia. Am. J. Psychiatry 134: 759-762.

Frith, C.D., Leary, J., Cahill, C., and Johnstone, E.C. 1991. Performance on psychological tests. Demographic and clinical correlates of the results of these tests. Br. J. Psychiatry Suppl. 13: 26-29, 44-46.

Gabrieli, J.D.E., Fleischman, D.A., Keane, M.M., and Reminger, S.L. 1995 Double dissociation between memory systems underlying explicit and implicit memory in the human brain. Psychol. Sci. 6: 76-82.

Goldberg, T.E., Kelsoe, J.R., Weinberger, D.R., Pliskin, N.H., Kirwin, P.D., and Berman, K.F. 1988. Performance of schizophrenic patients on putative neuropsychological tests of frontal lobe function. Int. J. Neurosci. 42: 51-58.

Goldberg, T.E., Saint-Cyr, J.A., and Weinberger, D.R. 1990. Assessment of procedural learning and problem solving in schizophrenic patients by Tower of Hanoi type tasks. J. Neuropsychiatry Clin. Neurosci. 2: $165-173$.

Goldberg, T.E., Torrey, E.F., Gold, J.M., Ragland, J.D., Bigelow, L.B., and Weinberger, D.R. 1993. Learning and memory in monozygotic twins discordant for schizophrenia. Psychol. Med. 23: 71-85.

Grafton, S.T., Mazziotta, J.C., Presty, S., Friston, K.J., Frackowiak, R.S., and Phelps, M.E. 1992. Functional anatomy of human procedural learning determined with regional cerebral blood flow and PET. J. Neurosci. 12: $2542-2548$.

Grafton, S.T., Woods, R.P., and Tyszka, M. 1994. Functional imaging of procedural motor learning: Relating cerebral blood flow with individual subject performance. Hum. Brain Mapp. 1: 221-234.

Granholm, E., Bartzokis, G., Asarnow, R.F., and Marder, S.R. 1993. Preliminary associations between motor procedural learning, basal ganglia T2 relaxation times, and tardive dyskinesia in schizophrenia Psychiatry Res. 50: 33-44.

Gras-Vincendon, A., Danion, J.M., Grange, D., Bilik, M., Willard-Schroeder, D., Sichel, J.P., and Singer, L. 1994. Explicit memory, repetition priming and cognitive skill learning in schizophrenia. Schizophr. Res. 13: 117-126.

Heinz, A., Knable, M.B., Coppola, R., Gorey, J.G., Jones, D.W., Lee, K.S., and Weinberger, D.R. 1998. Psychomotor slowing, negative symptoms and dopamine receptor availability - an IBZM SPECT study in neuroleptic-treated and drug-free schizophrenic patients. Schizophr Res. 31: 19-26.

Hildebrandt, H., Brand, A., and Sachsenheimer, W. 1998. Profiles of patients with left prefrontal and left temporal lobe lesions after cerebrovascular infarctions on California Verbal Learning Test-like indices. J. Clin. Exp. Neuropsychol. 20: 673-683.

Holm, S. 1979. A simple sequentially rejective multiple test procedure Scandinavian J. Stat. 6: 65-70.

Horn, A.S. and Snyder, S.H. 1971. Chlorpromazine and dopamine: Conformational similarities that correlate with the antischizophrenic activity of phenothiazine drugs. Proc. Natl. Acad. Sci. 68: 2325-2328.

Howard, D.V. and Howard, J.H. 1989. Age differences in learning serial patterns: Direct versus indirect measures. Psychol. \& Aging 4: 357-364.

Huston, P.E. and Shakow, D. 1949. Learning capacity in schizophrenia. Am. J. Psychiatry 105: 881-888.
Johnston, D.W. and Bursill, A.E. 1973. Probability learning and width of attention in normal and schizophrenic groups. Br. J. Soc. Clin. Psychol. 12: $402-410$.

Kapur, S. and Seeman, P. 2001. Does fast dissociation from the dopamine $\mathrm{D}(2)$ receptor explain the action of atypical antipsychotics? A new hypothesis. Am. J. Psychiatry 158: 360-369.

Kay, S.R., Fiszbein, A, and Opler, L.A. 1987. The positive and negative syndrome scale (PANSS) for schizophrenia. Schizophr. Bull. 13: 261-276.

Keane, M.M., Gabrieli, J.D., Mapstone, H.C., Johnson, K.A., and Corkin, S. 1995. Double dissociation of memory capacities after bilateral occipital-lobe or medial temporal-lobe lesions. Brain 118: 1129-1148.

Keri, S., Kelemen, O., Szekeres,G., Bagoczky, N., Erdelyi, R., Antal, A., Benedek, G., and Janka, Z. 2000. Schizophrenics know more than they can tell: Probabilistic classification learning in schizophrenia. Psychol. Med. 30: 149-155.

Kern, R.S., Green, M.F., and Wallace, C.J. 1997. Declarative and procedural learning in schizophrenia: A test of the integrity of divergent memory systems. Cogn. Neuropsych. 2: 39-50.

Knowlton, B.J., Squire, L.R., and Gluck, M.A. 1994. Probabilistic classification learning in amnesia. Learn. Mem. 1: 106-120.

Knowlton, B.J., Mangels, J.A., and Squire, L.R. 1996a. A neostriatal habit learning system in humans. Science 273: 1399-1402.

Knowlton, B.J., Squire, L.R., Paulsen, J.S., Swerdlow, N.R., and Swenson, M. 1996b. Dissociations within nondeclarative memory in Huntington's disease. Neuropsychology 10: 538-548.

Kremen, W.S., Seidman, L.J., Faraone, S.V., Pepple, J.R., Lyons, M.J., and Tsuang, M.T. 1996. The " 3 Rs" and neuropsychological function in schizophrenia: An empirical test of the matching fallacy. Neuropsychology 10: 22-31.

Laruelle, M., Abi-Dargham, A., van Dyck, C.H., Gil, R., D'Souza, C.A., Erdos, J., McCance, E., Rosenblatt, W., Fingado, C., Zoghbi, S.S., et al. 1996. Single photon emission computerized tomography imaging of amphetamine-induced dopamine release in drug-free schizophrenic subjects. Proc. Natl. Acad. Sci. 93: 9235-9240.

Lindstrom, L.H., Gefvert, O., Hagberg, G., Lundberg, T., Bergstrom, M., Hartvig, P., and Langstrom, B. 1999. Increased dopamine synthesis rate in medial prefrontal cortex and striatum in schizophrenia indicated by L-(beta-11C) DOPA and PET. Biol. Psychiatry 46: 681-688.

Lubin, A., Gieseking, C.F., and Williams, H.L. 1962. Direct measurement of cognitive deficit in schizophrenia. J. Consul. Psychol. 26: 139-143.

Martone, M., Butters, N., Payne, M., Becker, J.T., and Sax, D.S. 1984. Dissociations between skill learning and verbal recognition in amnesia and dementia. Arch. Neurol. 41: 965-970.

McDonald, R.J. and White, N.M. 1993. A triple dissociation of memory systems: Hippocampus, amygdala, and dorsal striatum. Behav. Neurosci. 107: 3-22.

Meyer-Lindenberg, A., Miletich, R.S., Kohn, P.D., Esposito, G., Carson, R.E., Quarantelli, M., Weinberger, D.R., and Berman, K.F. 2002. Reduced prefrontal activity predicts exaggerated striatal dopaminergic function in schizophrenia. Nat. Neurosci. 5: 267-271.

Michel, L., Danion, J.M., Grange, D., and Sandner, G. 1998. Cognitive skill learning and schizophrenia: Implications for cognitive remediation. Neuropsychology 12: 590-599.

Milner, B. 1963. Effects of different brain lesions on card sorting. Arch. Neuro.l 9: 100-110.

Mirsky, A., Lochhead, S., Jones, B., Kugelmass, S., Walsh, D., and Kendler, K. 1992. On familial factors in the attentional deficit in schizophrenia: A review and report of two new subject samples. J. Psychiatr. Res. 26: 383-403

Missar, C.D., Gold, J.M., and Goldberg, T.E. 1994. WAIS-R short forms in chronic schizophrenia. Schizophr. Res. 12: 247-250.

Moscovitch, M. 1992. A neuropsychological model of memory and consciousness. In Neuropsychology of memory, (eds. L.R. Squire and N. Butters), 2nd ed., pp. 5-22. Guilford, New York, NY.

Mutter, S.A. and Pliske, R.M. 1994. Aging and Illusory correlation in judgements of co-occurrence. Psychol. E Aging 9: 53-63.

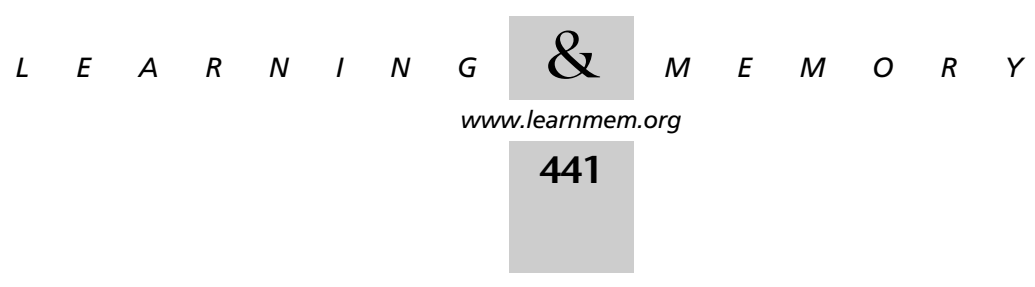


Nelson, H.E.and McKenna, P. 1975. The use of current reading ability in the assessment of dementia. Br. J. Soc. Clin. Psychol. 14: 259-267.

Nelson, H.E. and O'Connell, A. 1978. Dementia: The estimation of premorbid intelligence levels using the New Adult Reading Test. Cortex 14: 234-244.

Nelson, H.E., Pantelis, C., Carruthers, K., Speller, J., Baxendale, S., and Barnes, T.R. 1990. Cognitive functioning and symptomatology in chronic schizophrenia. Psychol. Med. 20: 357-365.

Packard, M.G. and McGaugh, J.L. 1992. Double dissociation of fornix and caudate nucleus lesions on acquisition of two water maze tasks: Further evidence for multiple memory systems. Behav. Neurosci. 106: 439-446.

Packard, M.G., Hirsh, R., and White, N.M. 1989. Differential effects of fornix and caudate nucleus lesions on two radial maze tasks: Evidence for multiple memory systems. J. Neurosci. 9: 1465-1472.

Palmer, B.W., Heaton, R.K., Paulsen, J.S., Kuck, J., Braff, D., Harris, M.J., Zisook, S., and Jeste, D.V. 1997. Is it possible to be schizophrenic yet neuropsychologically normal? Neuropsychology 11: 437-446.

Phillips, L.H., Wynn, V., Gilhooly, K.J., Della Sala, S., and Logie, R.H. 1999. The role of memory in the Tower of London task. Memory 7: 209-231.

Pickar, D., Su, T.P., Weinberger, D.R., Coppola, R., Malhotra, A.K., Knable, M.B., Lee, K.S., Gorey, J., Bartko, J.J., Breier, A., and Hisao, J. 1996. Individual variation in $\mathrm{D} 2$ dopamine receptor occupancy in clozapine-treated patients. Am. J. Psychiatry 153: 1571-1578.

Pilowsky, L.S., Costa, D.C., Ell, P.J., Verhoeff, N.P., Murray, R.M., and Kerwin, R.W. 1994. D2 dopamine receptor binding in the basal ganglia of antipsychotic-free schizophrenic patients. An 123I-IBZM single photon emission computerised tomography study. $\mathrm{Br} . \mathrm{J}$. Psychiatry 164: 16-26.

Poldrack, R.A., Prabhakaran, V., Seger, C.A., and Gabrieli, J.D. 1999. Striatal activation during acquisition of a cognitive skill. Neuropsychology 13: 564-574.

Poldrack, R.A., Clark, J., Pare-Blagoev, E.J., Shohamy, D., Creso Moyano, J., Meyers, C., and Gluck, M.A. 2001. Interactive memory systems in the human brain. Nature 414: 546-550.

Schacter, D.L., Chiu, C.Y., and Ochsner, K.N. 1993. Implicit memory: a selective review. Annu. Rev. Neurosci. 16: 159-182.

Schwartz, B.L., Rosse, R.B., Veazey, C., and Deutsch, S.I. 1996. Impaired motor skill learning in schizophrenia: Implications for corticostriatal dysfunction. Biol. Psychiatry 39: 241-248.

Schwartzman, A.E. and Douglas, V.I. 1962. Intellectual loss in schizophrenia: Part I. Canadian J. Psychol. 16: 1-10.

Seeman, P. 1987. Dopamine receptors and the dopamine hypothesis of schizophrenia. Synapse 1: 133-152.

Seeman, P. and Niznik, H.B. 1990. Dopamine receptors and transporters in Parkinson's disease and schizophrenia. FASEB J. 4: 2737-2744.

Seeman, P., Guan, H.C., and Niznik, H.B. 1989. Endogenous dopamine lowers the dopamine D2 receptor density as measured by [3H]raclopride: Implications for positron emission tomography of the human brain. Synapse 3: 96-97.

Smith, J., Oswald, W., Kucharski, L., and Waterman, L. 1978. Tardive dyskinesia: Age and sex differences in hospitalized schizophrenics. Psychopharmacology 58: 207-211.

Squire, L.R. 1992a. Declarative and nondeclarative memory: Multiple brain systems supporting learning and memory. J. Cogn. Neurosci. 4: $232-243$.

- 1992b. Memory and the hippocampus: A synthesis from findings with rats, monkeys, and humans. Psychol. Rev. 99: 195-231.

Ungerleider, L.G. 1995. Functional brain imaging studies of cortical mechanisms for memory. Science 270: 769-775.

Vakil, E. and Agmon-Ashkenazi, D. 1997. Baseline performance and learning rate of procedural and declarative memory tasks: Younger versus older adults. J. Gerontol. Psychol. Sci. 52B: P229-P234.

Weickert, T.W., Goldberg, T.E., Gold, J.M., Bigelow, L.B., Egan, M.F., and Weinberger, D.R. 2000. Cognitive impairments in patients with schizophrenia displaying preserved and compromised intellect. Arch. Gen. Psychiatry 57: 907-913.

Welsh, M.C., Satterlee-Cartmell, T., and Stine, M. 1999. Towers of Hanoi and London: Contribution of working memory and inhibition to performance. Brain Cogn. 41: 231-242.

Winter, W.E., Broman, M., Rose, A.L., and Reber, A.S. 2001. The assessment of cognitive procedural learning in amnesia: Why the tower of Hanoi has fallen down. Brain Cogn. 45: 79-96.

Received April 14, 2002; accepted in revised form August 22, 2002.

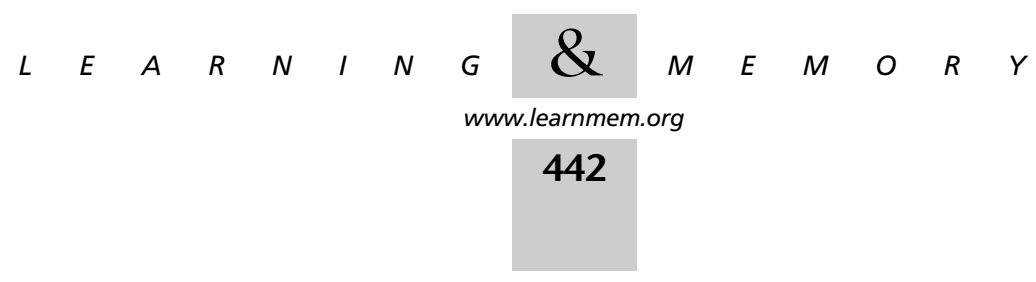




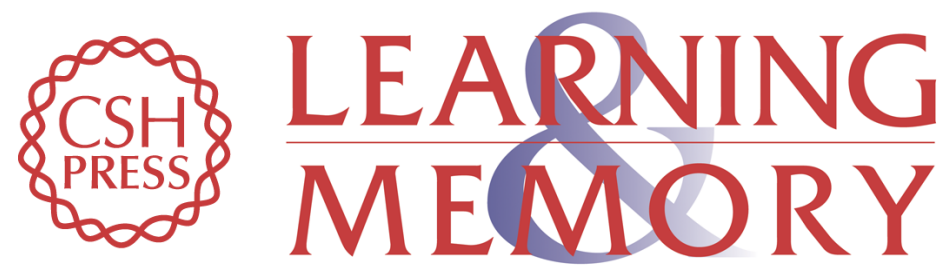

\section{Habit and Skill Learning in Schizophrenia: Evidence of Normal Striatal Processing With Abnormal Cortical Input}

Thomas W. Weickert, Alejandro Terrazas, Llewellyn B. Bigelow, et al.

Learn. Mem. 2002, 9:

Access the most recent version at doi:10.1101//m.49102

References This article cites 70 articles, 11 of which can be accessed free at:

http://learnmem.cshlp.org/content/9/6/430.full.html\#ref-list-1

License

Email Alerting Receive free email alerts when new articles cite this article - sign up in the box at the top Service right corner of the article or click here. 